\section{Envelhecimento populacional, cuidado e cidadania: velhos di- lemas e novos desafios}

Berlindes Astrid Küchemann ${ }^{1}$
Recebido:

06.12.11

Aprovado:

07.04.12

1. Professora associada do Departamento de Sociologia da Universidade de Brasília.

E-mail: astrid@unb. br

Resumo: O Brasil é um país que envelhece a passos largos. Em 2011, a população idosa era de 20,5 milhões, o equivalente a $10,8 \%$ da população total. Projeções indicam que, em 2020, a população idosa brasileira será de 30,9 milhões, representando $14 \%$ da população total. Esse envelhecimento acelerado vem produzindo necessidades e demandas sociais que requerem respostas políticas adequadas do estado e da sociedade. Dentre os inúmeros desafios a serem enfrentados está a questão do cuidado. As políticas públicas de amparo aos/às idosos/as consideram a família, o estado e a sociedade igualmente responsáveis pelo cuidado. Na prática, o mesmo tem sido visto como uma questão privada e não pública, cabendo, sobretudo, à família, materializada na figura da mulher, a tarefa de cuidar dos/as idosos/as. Este trabalho tem por objetivo, mostrar o quão inadequado é esse modelo que elege as mulheres como únicas responsáveis pelo cuidado e explora as possibilidades de um modelo que permita um envelhecimento com cidadania, no qual atuem família, estado e outros atores da sociedade.

Palavras-chave: Envelhecimento Populacional, Idosos/as, Cuidado, Cidadania, Cuidadoras Familiares.

\title{
Introdução
}

$\mathrm{S}$ egundo o censo demográfico de 2010 (IBGE, 2011), a população brasileira de hoje é de 190.755 .199 milhões de pessoas, sendo que $51 \%$, o equivalente a 97 milhões, são mulheres e 49\%, o equivalente a 93 milhões, são homens. O contingente de pessoas idosas, que, segundo a Política Nacional do Idoso e o Estatuto do Idoso, tem 60 anos a mais, é de 20.590 .599 milhões, ou seja, aproximadamente $10,8 \%$ da população total. Desses, 55,5 \% (11.434.487) são mulheres e 44,5\% (9.156.112) são homens.

O Brasil é um país que envelhece a passos largos. As alterações na dinâmica populacional são claras, inequívocas e irreversíveis. Desde os anos 1940, é entre a população idosa que temos observado as taxas mais altas de crescimento populacional. Na década de 50 , a taxa de crescimento da população idosa atingiu valores superiores a 3\% ao ano, chegando a 3,4\%, entre 1991 e 2000 . Ao 
compararmos, num intervalo de 25 anos (1980 a 2005), o crescimento da população idosa com o crescimento da população total, observamos que o crescimento da população idosa foi de $126,3 \%$, ao passo que o crescimento da população total foi de apenas 55,3\%. Nesse mesmo intervalo, o segmento de 80 anos a mais cresceu a um ritmo relativamente maior do que a população idosa total, apresentando um crescimento de $246,0 \%$ (INOUYE et alii, 2008, p. 12). Hoje, a faixa etária de 80 anos a mais é composta por 2.935 .585 pessoas (IBGE, 2011), representando $14 \%$ da população idosa brasileira.

De acordo com Beltrão, Camarano e Kanso (2004), espera-se que o contingente de idosos atinja a magnitude de aproximadamente 30,9 milhões de pessoas, no ano de 2020 , vindo a constituir $14 \%$ da população brasileira, ocupando, então, o sexto lugar na classificação mundial (INOUYE et alii, 2008, p. 15). Essa alta taxa de crescimento fez com que, na virada do século, a população brasileira de idosos/as apresentasse um crescimento oito vezes maior quando comparada às taxas de crescimento da população jovem (CAMARANO et alii, 1999). Caso seja mantida a atual dinâmica, a partir de 2030, o total de idosos/as ultrapassará o número de jovens entre 15 e 29 anos (IPEA apud BRASIL, 2010, p. 51).

Observando os dados da atual transição demográfica brasileira sob a ótica de gênero, constatamos um processo de feminização da velhice, ou seja, quanto mais a população envelhece, mais feminina ela se torna. Hoje, as mulheres representam 55,5\% da população idosa brasileira e $61 \%$ do contingente de idosos acima de 80 anos (IBGE, 2011). Essa sobrerrepresentação feminina resulta da maior expectativa de vida das mulheres que, em média, vivem 8 anos a mais que os homens. Dentre os fatores que concorrem para esse fenômeno, especialistas destacam as mortes violentas (assassinatos e acidentes), cujas vitimas, quando jovens e adultas, são homens em mais de $90 \%$ dos casos e o acompanhamento médico contínuo maior entre as mulheres do que entre os homens ao longo de suas vidas (BANDEIRA, MELO \& PINHEIRO, 2010).

A predominância do sexo feminino entre os idosos e, sobretudo, entre os idosos acima de 80 anos, faz crer que sejam elas as maiores dependentes de cuidados com repercussões importantes nas demandas por políticas públicas. Atualmente, a maioria dessas mulheres são viúvas, sem ou com pouca experiência de trabalho no mercado formal, com reduzido grau de escolaridade e apresentam as piores condições de saúde (CAMARANO, 2004, p. 38).

\section{O trabalho do cuidado e o destacado papel das cuidadoras familiares informais}

O aumento da expectativa de vida apresenta duas facetas. Por um lado, reflete 
mudanças culturais e avanços obtidos em relação à saúde e às condições de vida, tais como: redução da taxa de fecundidade, queda da mortalidade infantil, hábitos alimentares mais saudáveis e maior cuidado com o corpo. Por outro, aponta para a possibilidade do/a idoso/a ser acometido por doenças degenerativas e crônicas, que o/a torna sem autonomia, ou seja, dependente de cuidados de alguém. Estudos feitos na área da saúde (KARSCH, 1998; 2003) indicam que, na virada do século, cerca de $40 \%$ dos indivíduos com 65 anos ou mais precisavam de algum tipo de ajuda para realizar tarefas como fazer compras, cuidar das finanças, preparar refeições e limpar a casa. Uma parcela menor (10\%) foi considerada com falta de autonomia para realizar tarefas básicas, como tomar banho, vestir-se, ir ao banheiro, alimentar-se, sentar e levantar de cadeiras e camas. Passados nem dez anos, a proporção dessa parcela aumentou em, aproximadamente, $5 \%$, perfazendo um total de $15 \%$ (3,2 milhões) da população idosa atual, sendo que, desses 3,2 milhões, 2 milhões (63\%) são mulheres (IPEA, 2010). Esses dados indicam que o trabalho do cuidado está ganhando cada vez mais importância na sociedade brasileira.

Cuidar ou ser cuidado constitui uma questão central na vida de todos nós. Em momentos os mais diversos, todos nós cuidamos ou necessitamos do cuidado de alguém. Cuidar implica algum tipo de responsabilidade e compromisso e, quando uma pessoa ou um grupo cuida de alguém, é porque está "disposto a trabalhar, a se sacrificar, a gastar dinheiro, a mostrar envolvimento emocional e despender energia em relação ao objeto de cuidados" (TRONTO, 1997, p. 188). Cuidar também significa aproximar-se, estar presente e valorizar o/a outro/a com a devida atenção à sua individualidade. Cuidar é, pois, uma atividade que possibilita um encontro dialógico entre o ser que cuida e o ser que é cuidado. Levando-se em consideração que, com o avanço da idade, o idoso e a idosa podem sofrer graduais perdas cognitivas, apresentarem mudanças comportamentais e emocionais, a atividade do cuidado não pode ser uma atividade movida meramente por questões humanitárias ou éticas. Requer competências específicas para o seu exercício e boas condições de saúde de quem a exerce.

Historicamente, em países que vivenciaram essa transição demográfica de forma mais lenta, tais como França, Inglaterra e Alemanha, têm sido implementadas diversas formas de apoio e de cuidados aos idosos e às idosas. Em graduações variadas, as responsabilidades são divididas entre o setor público e o privado. Incluem políticas e serviços previdenciários, benefícios de organizações sindicais, de agências e unidades sanitárias estatais, assim como de organizações particulares de seguro-saúde (KARSCH, 2003).

No Brasil, a Constituição de 1988, a Política Nacional (1994) do Idoso e o Estatuto do Idoso (2003) consideram que o suporte aos idosos e às idosas seja da responsabilidade da família, do Estado e da sociedade. As leis e medidas 
elaboradas pelo Estado têm por objetivos proteger o/a idoso/a, fornecer subsídios que garantam sua participação na comunidade, defender sua dignidade, zelar pelo seu bem-estar e garantir o direito à vida. No entanto, apesar de o Estado prover alguns serviços básicos de saúde para a população da terceira idade, a cobertura dos serviços é deveras insuficiente, sobretudo, em se tratando de serviços e alojamentos para cuidados de longa duração e para necessidades não cobertas pelos planos de saúde. Serviços de atenção integral, como, por exemplo, residências ou centros de recreação, são poucos e restritos a setores de nível socioeconômico mais altos, capazes de custear tais serviços.

A participação do Estado brasileiro é apenas pontual e com reduzidas responsabilidades, quando comparadas às responsabilidades das famílias. Por falta de recursos de ordem financeira que permitam a contratação de cuidadores/as especializados/as, que atendam no ambiente familiar, os cuidados aos/às idosos/ as geralmente são realizados por um membro da família, em sua grande maioria uma mulher que reside no mesmo domicílio ou próximo do domicilio do/a idoso/a.

Nos países supracitados, nos quais o envelhecimento populacional tem sido mais lento e tem recebido a devida atenção durante décadas, encontramos uma rede de organizações que se define community care, cujo objetivo é manter o/a idoso/a em sua casa, oferecendo suportes para a família e o/a cuidador/a. Entre as diferentes modalidades de assistência ao/à cuidador/a familiar, estão, entre outros, o serviço de um profissional para alternar os cuidados com o/a cuidador/a familiar, a redução da jornada de trabalho do cuidador/a familiar e o recebimento de uma ajuda, em dinheiro, para suprir os gastos com a assistência prestada ao seu idoso e à sua idosa. Um programa largamente divulgado é o da "comida sobre rodas", que produz e distribui refeições programadas para idosos/as que moram sozinhos/as, idosos/as enfermos/as ou com pouca autonomia, poupando o/a idoso/a e o/a cuidador/a da tarefa de cozinhar todos os dias.

No Brasil, serviços de apoio dessa natureza ainda são raros, por não haver uma política referente aos papéis atribuídos às famílias e ao apoio que cabe a uma rede de serviços oferecer ao/à idoso/a dependente e aos seus familiares (KARS$\mathrm{CH}, 2003)$. No entanto, se queremos que nossos idosos e nossas idosas permaneçam no convívio familiar com um atendimento de qualidade, os/as cuidadores/as familiares de idosos/as dependentes deveriam ser alvo de orientação, capacitação e supervisão. Deveriam receber em casa visitas periódicas de médicos, enfermeiros, fisioterapeutas, nutricionistas e demais profissionais afins. Ademais, ao serem propostos cuidados familiares, caberia examinar a estrutura familiar na qual o/a idoso/a se insere, haja vista que a família, como veremos mais adiante, nem sempre está em condições de prestar os devidos cuidados. 
Desta feita, o trabalho do cuidado aos/às idosos/as deve ser encarado tanto do ponto de vista da pessoa que recebe cuidados, como da pessoa que cuida. Deve contemplar não somente a qualidade dos serviços oferecidos aos/às idosos/as por seus familiares, como também o impacto que as tarefas do cuidado têm na qualidade de vida dos/as cuidadores/as familiares.

Estudos feitos na área da saúde têm mostrado um quadro nada alentador a respeito dos/as familiares que cuidam de idosos/as. Além de nem sempre estarem preparados/as para prestarem um trabalho à altura do necessário, os/as mesmos/as nem sempre apresentam boa saúde, como mostra um estudo realizado no município de São Paulo (KARSCH, 1998), com 102 pessoas acima de 50 anos, que sofreram o primeiro episódio de acidente vascular cerebral (AVC). Esse estudo revelou que em $98 \%$ dos casos pesquisados, o/a cuidador/a era alguém da família. Dentre esses familiares, 92,9\% eram mulheres: 44,1\% eram esposas, $31,3 \%$ eram filhas e, em menor proporção, noras ou irmãs. Apesar de serem as principais atrizes na dinâmica dos cuidados pessoais diários dos portadores de AVC dos pesquisados, 67,9\% prestava esses cuidados sem nenhum tipo de apoio. Além do mais, $59 \%$ dessas cuidadoras tinham acima de 50 anos e $41 \%$ entre 60 e 80 anos, o que indica que pessoas idosas estão cuidando de idosos/as. Quanto às condições físicas dessas cuidadoras, o estudo revelou que as mesmas são doentes em potencial e que sua capacidade funcional deixa a desejar: 40,7\% tinha dores lombares, 39,0\% depressão, 37,3\% sofria de pressão alta, 37,3\% tinha artrite e reumatismo, 10,2\% problemas cardíacos e 5,1\%, diabete.

De um único estudo apenas não podemos inferir como anda a saúde dos/as cuidadores/as no Brasil. No entanto, os dados acima nos remetem a uma importante questão que é a dos impactos causados em pessoas que cuidam de um indivíduo idoso e incapacitado durante 24 horas. Recordando que ser cuidador/a familiar demanda trabalho, tempo, energia, recursos financeiros, carinho, esforço, boa vontade e paciência, podemos concluir que cuidar de um/a idoso/a dependente e fragilizado/a não pode ser tarefa para uma pessoa apenas, e muito menos para uma cuidadora familiar, idosa ou não, despreparada profissionalmente e que não dispõe de serviços de apoio e de uma política de proteção para o desempenho dessa atividade. Ou seja, o trabalho do cuidado necessita ser repensado e reestruturado com vistas a atender adequadamente às necessidades e às expectativas tanto daqueles e daquelas que necessitam de cuidados, quanto daqueles e daquelas que prestam cuidados. 


\section{As principais, contudo pouco visíveis, atrizes da dinâmica do cuidado aos idosos e às idosas}

Embora possamos observar mudanças de comportamento devido à crescente inserção das mulheres no mercado de trabalho, aos inúmeros novos arranjos familiares, ao crescente número de mulheres que, na condição de chefe ou de cônjuge, contribuem com a provisão dos recursos para a família e ao intensivo questionamento das feministas acerca dos papéis tradicionais de gênero, segue sendo hegemônica a compreensão de que o trabalho doméstico, a socialização das crianças e o cuidado aos/às idosos/as e doentes são de responsabilidade quase que exclusiva das mulheres.

Segundo dados da PNAD de $2008,87,9 \%$ das mulheres e $46,1 \%$ dos homens inseridos no mercado de trabalho declararam que executam afazeres domésticos e tarefas relacionadas aos cuidados com os membros familiares do domicílio. Quanto à intensidade com que homens e mulheres se dedicam aos afazeres reprodutivos, as mulheres estimaram dedicar 20,9 horas semanais às atividades domésticas e ao cuidado de seus familiares, e os homens 9,2 horas semanais (BRASIL, 2010, p. 57). Observa-se, pois, que tanto o contingente de mulheres que se dedicam ao trabalho reprodutivo quanto o número de horas que gastam é bem maior, quando comparados à população masculina. Há, pois, uma clara sobrecarga por parte das mulheres e essa sobrecarga influenciará decisivamente sobre o trabalho que elas realizam, ou desejam realizar no mercado de trabalho. Não nos surpreende, portanto, que, devido aos intensivos afazeres domésticos, as mulheres encontrem como alternativa o emprego em jornadas de trabalho menores que, por conseguinte, remuneram menos. Em 2007, 41\% das mulheres trabalhavam habitualmente menos de 40 horas, para apenas $18,6 \%$ dos homens (BRASIL, 2009, p. 16).

2. A metodologia utilizada partiu do pressuposto de que a remuneração média das/os trabalhadoras/os domésticas/os é o valor de mercado que a sociedade atribui aos prestadores desse serviço. Sendo assim, ao trabalho doméstico não remunerado aplicou-se a mesma valoração. Sobre essa metodologia, ver Melo, Considera e Sabatto (2007).
Esses dados revelam que, apesar dos esforços empreendidos para desnaturalizar os papéis socialmente construídos, o cuidado ainda é compreendido como um valor predominantemente feminino, realizado gratuitamente no âmbito familiar. Mas o cuidado também é exercido profissionalmente, tendo significativa expressão no campo da saúde, em especial na medicina e enfermagem, e no serviço social (SANTOS, 2003). Importante ressaltar que, quando exercido por profissionais dos serviços de cuidado ou por trabalhadoras domésticas remuneradas, as atividades vinculadas ao trabalho reprodutivo passam a ser contabilizadas no sistema de contas nacionais no valor equivalente ao de sua remuneração. Mas, se exercidas gratuitamente por alguém da própria família, deixam de ser mensuradas e, portanto, tornam-se invisíveis oficialmente. Se o trabalho reprodutivo exercido majoritariamente pelas mulheres fosse contabilizado, o PIB brasileiro, de 2008, aumentaria 10,3\%, segundo cálculos feitos a partir da PNAD/IBGE (BANDEIRA, MELO \& PINHEIRO, 2010, p. 112) 2 
Não é por mero acaso ou natural que cuidar e cuidados encontram na família um importante espaço onde os mesmos se expressam. Também não é por acaso ou natural que a pessoa cuidadora, geralmente, se materializa na figura da mulher. É que o cuidado é um trabalho e, portanto, não está alheio à divisão sexual do trabalho, que, por sua vez, norteia a organização social e econômica da sociedade. Como já apontamos anteriormente, o entendimento de que cabe às mulheres a responsabilidade das tarefas que compõem o trabalho reprodutivo deriva de uma divisão sexual do trabalho, dicotômica e pouco flexível, que atua como poderoso princípio norteador nas bases da organização social e econômica. Essa divisão do trabalho se manifesta em uma forma específica de relação entre trabalho produtivo remunerado e reprodutivo não-remunerado, na qual as noções de homem-provedor (força de trabalho principal) e mulher-cuidadora (força de trabalho secundária), são reforçadas. Manifesta-se, igualmente, na organização do mercado de trabalho, a partir da hierarquização estabelecida entre ocupações mais bem remuneradas e de maior prestígio social, entendidas como tipicamente masculinas e ocupações mal remuneradas e menos valorizadas socialmente, em grande parte associadas às tarefas de cuidado, tidas como tipicamente femininas. Esse entendimento, além de contribuir para que as mulheres enfrentem maiores dificuldades para se inserirem no mercado de trabalho e nos demais âmbitos da vida pública, possui, como bem lembra Vasconcelos, (2009, p. 37), "aspectos socioeconômicos e simbólicos que impactam na distribuição de recursos, bens e serviços e no poder de decisão sobre os mesmos, desempenhando papel central na reprodução das desigualdades sociais".

O entendimento de que cabe às mulheres a responsabilidade das tarefas que perfazem o trabalho reprodutivo contribui para alimentar a compreensão de que a reprodução social é uma responsabilidade das mulheres e não da sociedade. Para Vasconcelos (2009, p. 37), tal compreensão, além de minar uma divisão equitativa de responsabilidades entre homens e mulheres, influi também na definição de temas e prioridades das políticas públicas, resultando em uma não abordagem das questões do cuidado por parte do Estado e no consequente déficit dos serviços públicos endereçados à cobertura dessas tarefas. Ademais, a não consideração do trabalho reprodutivo como uma questão pública "promove o aprofundamento das desigualdades e alimenta o ciclo de reprodução da pobreza, na medida em que o acesso a serviços de cuidado fica disponível apenas para grupos sociais, cujos rendimentos permitem sua contratação" (VASCONCELOS, 2009, p. 37).

Hoje, cabe quase que exclusivamente às mulheres a tarefa de conciliar trabaIho produtivo e reprodutivo. Como contam com pouco apoio por parte do Estado, elas acabam por desenvolver uma série de ativos sociais para redistribuir algumas tarefas e, assim, satisfazer as necessidades práticas decorrentes da sua condição de cuidadora e promotora do bem-estar familiar (KÜCHEMANN, 
2001). Todo o esforço que despendem as torna mais eficientes no cumprimento do seu dever moral de cuidar de toda a família, mas, nem por isso, as torna menos sobrecarregadas.

\section{Novos desafios}

Aos velhos dilemas já apontados, tais como a sobrecarga de trabalho das muIheres e as dificuldades para conciliar o trabalho produtivo com o trabalho reprodutivo, a falta de infraestrutura familiar adequada a fim de acomodar os/as idosos/as dependentes e o despreparo para atender os/as idosos/as, há uma série de novos desafios, não apenas para as cuidadoras familiares informais, mas para a sociedade como um todo, incluindo o estado e o mercado. Dentre esses desafios destacamos dois:

1. A saída de cena da família tradicional e o surgimento de novos arranjos familiares

A família é uma das instituições mais importantes e eficientes no tocante ao bem estar dos indivíduos e à distribuição de recursos. Ela intermedeia parte da relação entre o mercado e os indivíduos, já que distribui rendimentos entre membros, assim como faz a intermediação entre o Estado e o indivíduo, redistribuindo, direta ou indiretamente, os benefícios recebidos. Reiteradas vezes temos falado sobre a importância da família, sobretudo o papel das cuidadoras familiares informais na dinâmica dos cuidados diários prestados aos/às idosos/ as da sociedade brasileira que não possuem autonomia para realizarem as mais triviais tarefas do cotidiano. Mas a qual família referem-se os profissionais de saúde e outros especialistas quando indicam cuidados em casa a idosos/as dependentes? Referem-se à família tradicional ou às inúmeras famílias reais de hoje?

Até pouco tempo atrás, a família era entendida como o conjunto de pessoas residentes sob o mesmo teto, e que, entre si, apresentam laços de parentesco e de afinidade. A ideia de família era associada a um modelo no qual o núcleo era composto por um casal heterossexual, cabendo ao homem o lugar de chefe e provedor da família e à mulher a atenção aos/às filhos/as, o gerenciamento do lar, o cuidado aos/às idosos/as e doentes. Acontece que esse modelo tradicional de família está desaparecendo, dando lugar a novos arranjos familiares, nem sempre favoráveis à acomodação de idosos/as. Separações, divórcios e novas uniões, participação crescente da mulher no mercado de trabalho, movimentos migratórios nacionais e internacionais em busca de oportunidades de trabaIho, aumento de famílias chefiadas por mulheres, idosos/as exercendo chefias 
de família e o aumento de famílias do tipo monoparental e unipessoal são apenas alguns dos aspectos geradores de novas estruturas familiares.

De fato, o tipo de arranjo familiar tradicional (homem-provedor, mulher-cuidadora) vem diminuindo significativamente ao longo dos anos: se, em 1992, representava quase $63 \%$ das famílias, em 2008 , caiu para $50,5 \%$ do total. Por outro lado, observa-se que, nesse mesmo período, houve um aumento expressivo da chefia feminina. A proporção de famílias tendo uma mulher, sem cônjuge, como chefe aumentou de 25,9\% (1992) para 34,9\% (2008); e de 2,4\% para 9,1\% a proporção de famílias chefiadas por mulheres com cônjuge (Ipea, apud BANDEIRA, MELO \& PINHEIRO, 2010, p. 110). Também tem aumentado o número de famílias constituídas por casais sem filhos ${ }^{3}$. Esse arranjo familiar passou de $11,7 \%$ para $15,7 \%$, entre 1998 e 2008 . É também pertinente observar que, nesse arranjo familiar, tem crescido o número de casais em que ambos auferem rendimentos. Em 1998, esses casais representavam 3,2\%, e, em 2008, 5,3\% do total de casais sem filhos, o equivalente a 2,1 milhões de famílias (BANDEIRA, MELO \& PINHEIRO, 2010, p. 111).

Ao leque de arranjos já apontados cabe mencionar os arranjos unipessoais, ou seja, de pessoas que vivem sozinhas. Se, em 1998, 8,4\% dos brasileiros não dividiam o teto com ninguém, esse índice aumentou para $11,6 \%$, em 2008 . Entre esses moradores solitários, cabe destacar a alta proporção de pessoas acima de 60 anos, sobretudo mulheres. Segundo Camarano (2003), em 2000, 13,5\% das mulheres idosas viviam sozinhas. Essa proporção cresce com a idade, atingindo aproximadamente $18 \%$ entre as com idade superior a 75 anos e é mais alta entre as mulheres separadas, seguidas das viúvas. Viver só pode ser um estágio temporário do ciclo de vida e pode estar refletindo preferências ${ }^{4}$.

Assim sendo, para os idosos, a opção por morarem sozinhos não necessariamente significa abandono, descaso ou solidão. Para Debert (1999), morar só pode representar uma forma inovadora e bem sucedida de envelhecimento e, para Camarano (2003), a redução na proporção de idosos vivendo em casa de parentes tem sido uma tendência crescente no tempo e permite inferir que há uma tendência de redução na dependência dos idosos.

$\mathrm{Na}$ verdade, o simples fato de os idosos morarem sozinhos pode representar uma maior autonomia, desde que tenham condições financeiras favoráveis e tenham uma boa saúde, pois a distância geográfica com os demais familiares (fiIhos, netos, irmãos) nem sempre pode ser traduzida por uma menor frequência de contato com os mesmos.

Como esses diversos novos arranjos familiares interferem na dinâmica do cuidado aos/às idosos/as? A quem, sobretudo, aqueles e aquelas que moram
3. "A opção por ter filhos tende a ser postergada, especialmente em função da decisão feminina de investir na vida acadêmica ou na carreira profissional, como uma etapa anterior à de ter filhos" (BANDEIRA et al., p. 111).

4. O aumento de arranjos unipessoais é uma tendência mundial e vale tanto para homens como para mulheres. $\mathrm{Na}$ Inglaterra, o índice de domicílios habitados por uma única pessoa é de $30 \%$. Nos Estados Unidos, alcança os $25 \%$. Em Nova York, a Meca dos/as solteiros/as, mais da metade da população $(50,6 \%)$ vive só (BANDEIRA et al., 2010, p. 111). 
sozinhos/as podem recorrer quando necessitam de apoio? Estão sendo geradas e implementadas novas formas de apoio aos/às idosos/as? Faltam pesquisas de fôlego para subsidiar respostas a essas e outras tantas indagações. Só de uma coisa temos certeza: já se foi o tempo em que se podia contar com um familiar para cuidar dos/as idosos/as, no tempo e na intensidade requeridos. Requer-se, pois, averiguar com urgência como esses novos arranjos familiares interferem na dinâmica do cuidado para, então, desenvolver novos enfoques de políticas públicas de saúde e de bem estar social.

2 Abandono do modelo que elege as mulheres como únicas responsáveis pelo cuidado.

Tudo indica que o velho dilema do feminismo ainda persiste e de que é preciso debruçar-se no desenho de políticas de abandono desse modelo que elege as mulheres como únicas responsáveis pelo trabalho reprodutivo. Poderia iniciar, por exemplo, repensando as políticas relativas à maternidade e às responsabilidades familiares centradas nas mulheres, que acabam reforçando a imagem de única cuidadora e de força de trabalho secundária, por sua vez, fonte da discriminação que as mulheres enfrentam no mercado de trabalho. Por que não estender a ambos os cônjuges as medidas e benefícios que não estão ligados à função exclusivamente biológica das mulheres (gravidez, parto, recuperação e amamentação), e incorporar os homens nas funções de cuidado aos/às filhos/as e aos/às idosos/as? Não seria essa uma política mais adequada do que aquela que, simplesmente, apela moralmente a uma distribuição mais equitativa de tarefas entre os sexos no espaço doméstico? O privado é político, diz um velho slogan do movimento feminista. A partir desse mote, porque não pensar em corresponsabilizar outros atores sociais no enfrentamento das tensões geradas, na tentativa de conciliar trabalho produtivo e reprodutivo? Em vez de continuar insistindo em soluções a partir do trabalho reprodutivo, por que não pensar em soluções advindas do trabalho produtivo, como por exemplo, a reorganização do trabalho produtivo a partir de um enfoque integrado de políticas públicas de conciliação, dirigidas tanto a trabalhadores como a trabalhadoras?

Há anos, preocupados com a elaboração de políticas a favor do trabalho decente, a Organização Internacional do Trabalho (OIT) publicou recentemente um relatório intitulado Trabalho e Família: rumo a novas formas de conciliação com co-responsabilidade social (OIT, 2009), no qual desenvolve uma ampla proposta nesse sentido. Dentre as inúmeras sugestões e recomendações apresentadas nesse relatório (p. 109-110), destacamos, a titulo de reflexão, algumas diretamente relacionadas ao trabalho do cuidado: 
a) Visibilizar e reconhecer o valor do trabalho doméstico não remunerado realizado pelas mulheres, particularmente, sua capacidade de cuidadoras de crianças, pessoas com deficiência e idosos, e também avaliar sua contribuição social e econômica;

b) Superar a concepção de que o cuidado é uma responsabilidade privada, da esfera do lar e das mulheres, redistribuindo as responsabilidades entre os domicílios, o mercado e o Estado, a fim de garantir uma maior participação da sociedade no processo de reprodução da força de trabalho;

c) Abandonar a ideia de que apenas as mulheres devam se preocupar com a conciliação entre trabalho produtivo e responsabilidades familiares, promovendo modelos alternativos de maternidade, paternidade e masculinidade como pré-requisito para o êxito das políticas de conciliação. Enquanto a maternidade estiver associada ao sacrifício e à onipresença com os filhos, dificilmente será possível alcançar uma redistribuição de tarefas de cuidado, bem como aliviar a sobrecarga que recai sobre as mães trabalhadoras. Requer, igualmente, dar ao papel dos homens na família o significado de pessoas afetivas, interessadas e capazes de assumir responsabilidades familiares, tais como: a criação dos filhos e das filhas, o cuidado aos/às idosos/as e familiares enfermos e a realização de tarefas domésticas;

d) Reconstruir amplamente o conceito de maternidade no mundo do trabalho, a partir da revalorização das tarefas associadas às funções de cuidado e da criação de novas formas de organização do trabalho e do tempo social;

e) "Em lugar de buscar a eqüidade promovendo, simplesmente a incorporação das mulheres a um mercado de trabalho estruturado por gênero, o fundamental é desconstruir o modelo do trabalhador ideal: homem, sem responsabilidades domésticas com sua família";

f) Modificar "a relação entre mercado e trabalho doméstico de forma que todos os adultos, homens e mulheres, possam alcançar seus ideais familiares e profissionais. Isso passa pela revalorização do trabalho das mulheres e uma desconstrução da percepção de que são força de trabalho secundária“;

g) Promover que os marcos legais proíbam a discriminação associada às responsabilidades familiares, entendendo que as licenças parentais e outras ausências temporárias, associadas às responsabilidades familiares, não constituam obstáculos para a manutenção do emprego e para o progresso nas carreiras profissionais. 
Em relação ao recorrente questionamento se as políticas devem ser específicas ou universais, o estudo da OIT, acima referido, propõe que "além da elaboração e implementação de políticas específicas, devem ser considerados os impactos indiretos de todas as políticas públicas sobre as tensões entre o âmbito familiar e profissional". Para tanto, "é necessário transformar toda ação de política pública em uma ferramenta que contribua para a desconstrução dos papéis tradicionais de gênero e para a incorporação da questão do cuidado". O estudo lembra, ainda, que "a integração de distintas políticas com efeitos conciliatórios pode potencializar os resultados das políticas setoriais e neutralizar efeitos não desejados de iniciativas isoladas", sendo, para tanto, necessário combinar estratégias bem definidas e de amplo alcance dirigidas a grupos com necessidades especiais, juntamente com outras que fortaleçam políticas universais em matéria de cuidado, de ampla cobertura e sustentadas por amplos pactos sociais e políticos (p. 108). Além do mais, "as políticas devem ser desenhadas de acordo com o contexto nacional, buscando as margens de ação que podem ser aproveitadas para avançar na promoção da conciliação e de uma socialização do trabalho de cuidado" e, para tanto, "o caráter conciliatório das políticas sociais setoriais existentes pode ser acentuado, por exemplo, nos programas focalizados destinados à população mais pobre" (p. 110).

Do acima exposto, podemos concluir que a Organização Internacional do TrabaIho entende que a conciliação entre trabalho produtivo e as responsabilidades familiares requer mudanças não apenas nas condições de emprego para mulheres, senão também, nas exigências e nos requisitos de desempenho profissional impostos a homens e mulheres no mundo do trabalho e mudanças nas condições do mercado de trabalho. Nesse sentido, podemos concluir que a proposta apresentada pela OIT nos remete não apenas a uma mudança de foco, senão a uma mudança de paradigma.

\section{Considerações finais}

Os idosos não vivem isolados: o seu bem-estar e o exercício de sua cidadania guardam estreita relação com a sociedade em que vivem. Devido ao acelerado crescimento da população idosa, a infraestrutura de cuidados aos/às idosos/as da sociedade brasileira exige equipamentos sociais e serviços cada vez mais eficientes e complexos. Por motivos vários, entre eles, a redução de custo da assistência hospitalar e institucional aos/às idosos/as, considerados/as dependentes, a tendência, hoje, é a de indicar a permanência dos/as mesmos/as em suas casas sob os cuidados de sua família. No entanto, essa recomendação não leva em consideração as mudanças ocorridas na sociedade brasileira, sobretudo em relação à configuração da estrutura familiar. Parte de um modelo 
estável de família nuclear e do pressuposto de que qualquer família pode contar com a disponibilidade de um de seus membros para assistir às necessidades dos/as idosos/as dependentes. Além da necessidade de se conhecer a estrutura familiar, delegar à família a função de cuidar de idosos/as requer estabelecer o tipo de cuidado a ser executado, o tempo necessário, as características da fragilidade do idoso/a, o tipo de apoio institucional e de acompanhamento profissional.

Acontece que, hoje, as famílias, sobretudo as mulheres, carecem de apoio institucional para oferecerem condições favoráveis para que os/às idosos/as tenham uma assistência à altura do merecido. E, provavelmente, essa situação tenderá a piorar enquanto o cuidado aos/às idosos/as não for considerado uma questão pública, de responsabilidade não apenas das famílias, mas também do Estado e da sociedade como um todo.

Assim sendo, tanto os cuidados quanto os/as cuidadores/as familiares deverão ser objeto de políticas e programas de saúde pública em parceria com inúmeras outras políticas públicas. É fundamental que o Estado brasileiro garanta uma infraestrutura de serviços em vários âmbitos de atuação das políticas públicas, favorecendo a todo um conjunto de medidas que possam garantir o bem estar dos/as idosos/as e o exercício de sua cidadania.

Enfim, é preciso encontrar um modelo que desonere as mulheres da responsabilidade de serem as responsáveis pela conciliação entre trabalho produtivo e reprodutivo, corresponsabilizando outros atores sociais no enfrentamento das tensões geradas, buscando soluções advindas do trabalho produtivo, em vez de continuar insistindo em soluções a partir do trabalho reprodutivo. Ou seja, pensar em políticas de conciliação entre trabalho e família, que partam de uma reformulação da divisão sexual do trabalho envolvendo os mais diversos atores sociais.

Abstract: Brazil is a country that ages increasingly. In 2011, the elderly population marks 20,5 million, equivalent to $10,8 \%$ of the entire population. Projections suggest that, in 2020, the elderly Brazilian population will be 30,9 million, representing 14\% of the whole population. This fast growing of the elderly population requires social services and demands appropriate political answers from both, the state and society. Among the many challenges to be faced is the one of the care services. The public policies for the elderly consider the family, the state and the society equally responsible for the care. In practical terms, this matter has been seen as a private and not a public issue, materializing in the figure of the woman, the job of looking after the elderly. The objective of this paper is to show how inadequate this model that elects women as the only responsible for the care is and also explores the possibilities of a new one that allows an aging process 
guided by civic values, in which the family, the state and other actors of society play their roles.

Keywords: Population Aging, Elderly, Care, Civic Values, Family Care Takers.

\section{Referências Bibliográficas}

AGUIRRE, R. "Los cuidados familiares como problema público y objeto de políticas". in Irma Arriagada (Coord.) Família y políticas públicas en América Latina: una história de desencuentros. Santiago de Chile: Cepal, 2007, p. 187-198.

ARAUJO, T. C. N.; ALVES, M. I. C. Perfil da população idosa no Brasil, in UNATI - Textos sobre envelhecimento, Vol. 3. n. 3, Rio de Janeiro, 2000.

BANDEIRA, L; MELO, H. P; PINHEIRO, L. S. "Mulheres em dados: o que informa a PNAD/ IBGE", 2008. in Observatório Brasil da Igualdade de Gênero, julho, 2010, p. 107- 119.

BELTRÃO, K. I.; CAMARANO, A. A.; KANSO, S. Dinâmica populacional brasileira na virada do século XX. Rio de Janeiro: IPEA, 2004a (Texto para Discussão, 1.034).

"Mudanças nas condições de vida dos idosos rurais brasileiros: resultados não-esperados dos avanços da Seguridade Rural". Trabalho apresentado no I Congresso da Associação Latino-Americana de População, realizado em Caxambu. MG, de 18 a 20 de setembro. 2004b.

BRASIL. SECRETARIA ESPECIAL DE POLITICAS PARA AS MULHERES. Com todas as mulheres por todos os seus direitos. Brasília: SPM, 2010.

BRASIL. SECRETARIA ESPECIAL DE POLITICAS PARA AS MULHERES. "Impactos da crise sobre a vida das mulheres", in Revista do Observatório Brasil da Igualdade de Gênero. 1a impressão. Brasília: SPM, 2009, p. 17-22.

CAMARAnO, A. A. et al. "Como vive o idoso brasileiro?", in CAMARANO, A. A. (org.). Muito além dos 60: os novos idosos brasileiros. Rio de Janeiro: IPEA, 1999.

CAMARANO, A. A. "Mulher idosa: suporte familiar ou agente de mudança?", in Estudos Avançados, vol. 17, n. 49, 2003, p. 35-64.

CAMARANO, A. A.; KANSO, S.; MELLO, J. L. "Como vive o idoso brasileiro?", in CAMARANO, A. A. (Org.) Os novos idosos brasileiros muito além dos 60? Rio de Janeiro: IPEA, 2004, p. 25-76.

CHAIMOWICZ, F. "A saúde dos idosos brasileiros às vésperas do século XXI: problemas, projeções e alternativas", in Revista de Saúde Pública, Vol. 31, n. 2, 1997, p. 184-200. 
CISNE, M.; GURGEL, T. "Feminismo, Estado e Políticas Públicas: desafios em tempos neoliberais para a autonomia das mulheres", in SER Social, Vol. 10, n. 22, 2008, p. 69- 96.

DEBERT, G. G. "Gênero, envelhecimento", in Estudos Feministas, n. 1, 1994, p. 33- 51.

. A reinvenção da velhice: socialização e processos de reprivatização do en-

velhecimento. São Paulo: Edusp/ Fapesp, 1999.

FERNANDES, M. das G. M.; GARCIA, T. R. "Atributos da tensão do cuidador familiar de idosos dependentes", in Revista da Escola de Enfermagem da USP, Vol. 43, n. 4, 2009.

INOUYE, K.; PEDRAZZANI, E. S.; PAVARINI, S. C. I. “Octogenários e cuidadores: perfil sóciodemográfico e correlação da variável qualidade de vida", in Texto contexto - Enfermagem, Vol. 17 n. 2, Florianópolis, 2008.

INSTITUTO BRASILEIRO DE GEOGRAFIA E ESTATÍSTICA - IBGE. Dados sobre População do Brasil, PNAD (Pesquisa Nacional por Amostra de Domicílios), 2001.

INSTITUTO BRASILEIRO DE GEOGRAFIA E ESTATÍSTICA - IBGE. Sinopse do Senso Demográfico de 2010. Rio de Janeiro, 2011.

INSTITUTO DE PESQUISA ECONÔMICA APLICADA - IPEA. Cuidados com idosos foram discutidos em seminário, 2010. www.ipea.gov.br. Consulta feita em 27/07/2010.

KALACHE, A.; VERAS, R.; RAMOS, L. R. "O envelhecimento da população mundial. Um desafio novo", in Revista Saúde Pública, 21 (3), 1987, p. 200-210.

KARSCH, U. M. "Idosos dependentes: famílias e cuidadores", in Cadernos de Saúde Pública, Vol.19, n. 3, Rio de Janeiro, 2003.

KÜCHEMANN, B. A. "Estratégias de Sobrevivência de Mulheres no Setor Informal Urbano", in KOHLHEPP, Gert (Coord.) Brasil: Modernização e Globalização. Madrid: Iberoamericana/ Frankfurt am Main: Vervuert Verlag, 2001, p. 155-174.

MEDINA, C.; SHIRASSU, M.; GOLDFEDER, M. "Das incapacidades e do acidente cerebrovascular". In: KARSCH, U. (org.) Envelhecimento com Dependência: Revelando Cuidadores. São Paulo: EDUC, 1998, p. 199-214.

MELO, H.; CONSIDERA, C. M.; SABATTO, A. "Os afazeres domésticos contam!", in Economia e Sociedade, Campinas, 2007.

MOREIRA, M. D.; CALDAS, C. P. "A importância do cuidador no contexto da saúde do idoso", in Escola Anna Nery, Vol. 11. n. 3, Rio de Janeiro, 2007.

ORGANIZAÇAO INTERNACIONAL DO TRABALHO - OIT. Trabalho e Familia: rumo a novas formas de conciliação com co-responsabilidade social. Brasília: OIT, 2009. 
RODRIGUEZ, G. "A autonomia econômica das mulheres e a reprodução social: o papel das políticas públicas", in Observatório Brasil da Igualdade de Gênero, 2010, p. 31-40.

SANTOS, T. S. dos. "Gênero e políticas sociais: novos relacionamentos sobre a estrutura familiar" in SER Social, Vol. 10, n. 22, 2008, p. 97-128.

TRONTO, J. "Mulheres e cuidados: o que as feministas podem aprender sobre a oralidade a partir disso?", in JAGGAR, Alison; BORDO, Susan (eds.) Gênero, corpo, conhecimento. Rio de Janeiro: Record; Rosa dos Tempos, 1997, p. 186-203.

VASCONCELOS, M. Responsabilidades familiares. In: Revista do Observatório Brasil da Igualdade de Gênero. Primeira Impressão. Brasília: Secretaria Especial de Políticas para as Mulheres, 2009, p. 36-43. 